\title{
Congenital facial palsy with anotia and congenital heart disease in infants: A rare presentation
}

\author{
Suhas Kulkarni ${ }^{1}$, Sachin Verma ${ }^{2}$, Saiprasad Onkareshwar Kavthekar ${ }^{3 *}$, Bhuwan Kumar Singh ${ }^{4}$ \\ ${ }^{1,3}$ Associate Professor, ${ }^{2,4}$ Junior Resident, ${ }^{1-4}$ Dept. of Pediatrics, D.Y. Patil Medical College and Hospital Kadamwadi, Kolhapur, \\ Maharashtra, India.
}

\section{*Corresponding Authors: Saiprasad Onkareshwar Kavthekar}

Email: dr.sachin120@gmail.com

\begin{abstract}
Developmental facial paralysis is associated with other anomalies including those of pinna and external auditory canal, ranging from mild defects to severe microtia and atresia and also associated with congenital heart defect. Here we report case series of three cases of developmental facial palsy which are associated with ear anomalies and congenital heart defects.
\end{abstract}

Keywords: Anotia, Congenital facial palsy, Congenital heart disease.

\section{Introduction}

Congenital Facial Palsy (CFP) is generally considered to be either developmental or acquired in origin. Developmental facial paralysis is associated with other anomalies including those of pinna and external auditory canal, ranging from mild defects to severe microtia and atresia and also associated with congenital heart defect. Most of the acquired facial palsy is due to birth injury.

\section{Case 1}
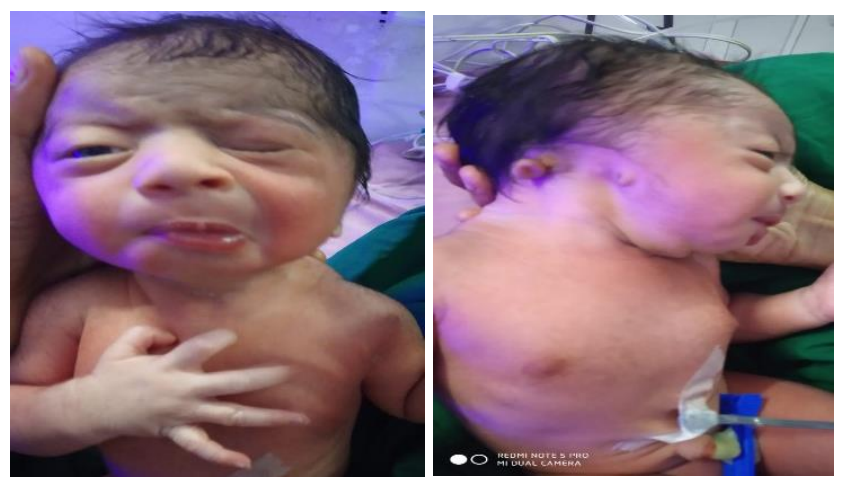

Fig. 1 and 2: Right facial paralysis associated with right side anotia and normal left side ear

A female full-term new born delivered by vaginal route with intrauterine growth retardation was admitted in the Neonatal Intensive Care Unit with anomaly at birth. There was no history suggestive of intrauterine infection or drug intake during pregnancy. Physical examination showed right side anotia with right preauricular tag and right lower motor neuron type of facial palsy (Fig. 1 and 2). There were no other cranial nerve palsies and the rest of the neurological examination was normal. Magnetic Resonance Imaging (MRI) brain was normal.

High-resolution CT temporal bone done to define the etiology of facial nerve palsy and revealed absence of pinna, non-visualization of right auditory canal and normal middle ear ossicles. Brainstem Evoked Response Audiometry
(BERA) showed bilateral peak " $\mathrm{V}$ " observed up to $40 \mathrm{db}$ NHL, moderate hearing loss on right side. 2-D ECHO showed acyanotic congenital heart disease, $1 \mathrm{~mm}$ atrial septal defect, and $5 \mathrm{~mm}$ moderate sized ventricular septal defect and both were having left to right shunt.

\section{Case 2}

4 months old baby born of normal full-term caesarean delivery was referred for ear anomalies. Physical examination showed bilateral anotia with bilateral auricular tags and bilateral lower motor neuron facial palsies (Fig. 3 and 4). Ultrasound abdomen was normal, MRI brain was also normal, BERA showed moderate NHL ranging 3050dbNHL.2-D ECHO showed Acyanotic congenital heart disease with ASD $1.5 \mathrm{~mm}$ (Left to Right shunt) and $1 \mathrm{~mm}$ patent ductus arteriosus.
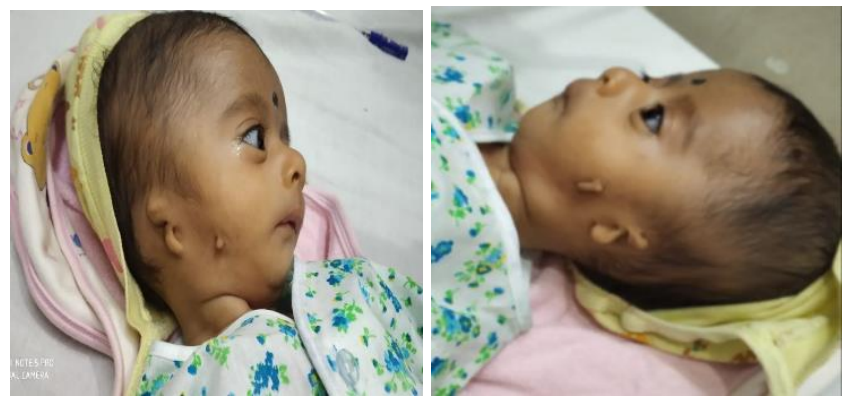

Fig. 3 and 4: Bilateral facial palsies with bilateral anotia

\section{Case 3}

2 month male baby born of normal full-term vaginal delivery brought by parent for ear anomaly. Bay had right anotia and right assymetric crying facies and normal left ear and rest of central nervous system examination was normal. MRI brain was normal. BERA showed moderate grade hearing loss upto $20 \mathrm{db}$. 2-D ECHO showed 2mm VSD with left to right shunt. 

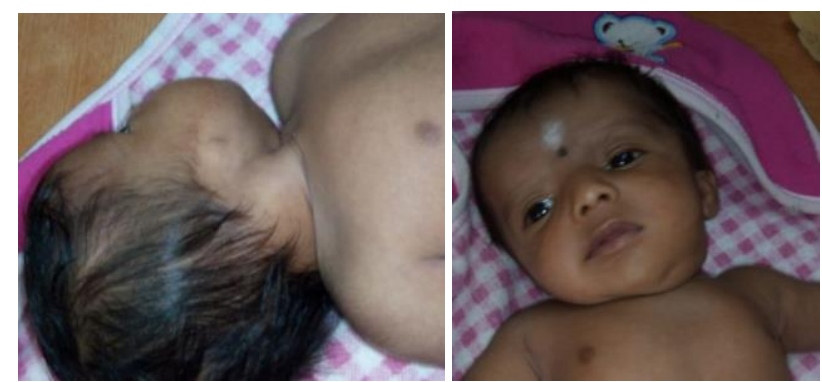

Fig. 5 and 6: Assymetric crying facies and anotia on right side

\section{Discussion}

Congenital facial nerve palsy is arare condition with incidence of 2.1 per 1,000 live births. ${ }^{2}$ In $78 \%$ cases, it is usally related to birth injury. Other causes, like intrauterine posture, intrapartum the velo-cardiofacial, Moebius syndrome, Poland's, syndrome and Goldenhaar's syndrome. ${ }^{1,3}$

Some cases of CFP, are attributed to agenesis of the petrous part of the temporal bone, resulting agenesis of $7^{\text {th }}$ and 8 thcranial nerves, the external ear and the mastoid region. ${ }^{4}$ Mostly, development facial paralysis is associated with other congenital anomalies. The most common site reported is the maxilla, which includes defects like cleft palate, duplication of the palate and hypoplastic maxilla. Others have reported increased anomalies of the pinna and external auditory canal varying from mild defects to severe microtia as well as atresia. ${ }^{1}$

An association of grossly abnormal pinna, multiple defects and facial palsy has been reported in 10-15\% of patients. Aural atresia occurs in nearly 1 in 20,000 live births. Atresia and microtia are parts of various syndromes with inherited defects or acquired embryopathies due to intrauterine infections like rubella, syphilis, ischemic injury such as hemifacial microsomia or due to toxin exposure like thalidomide, iso-tretinon. Aberration in the development of canaliculi process of external auditory canal, it can lead to stenosis, canal tortuosity or fibrous/osseous obliteration. Since middle ear structure develops independently, the tympanic cavity as well as ossicles maybe normal.

Defects in the canalization may be associated with faulty formation of pinna. ${ }^{5}$ Various surgical techniques are done for treatment of CFP. The ideal time for the intervention is controversial. Some clinicians advise early- preschool surgery for the animation of children's faces ${ }^{6,7}$ while others advocate surgery after adolescence. ${ }^{8}$

Muscle transplantation for facial paralysis has been proven to be effective. ${ }^{7}$ However, the chances of Reconstructive surgery are limited. Traumatic facial palsy in neonates is associated with good prognosis. ${ }^{9}$

\section{Conclusion}

Developmental congenital facial palsy is an infrequent condition and most of them are associated with ear and cardiac anomalies.

\section{Source of funding}

None.

\section{Conflict of interest}

None.

\section{References}

1. Bergstrom L, Baker BB. Syndromes associated with congenital facial paralysis. Otolaryngol-Head Neck Surg 1981;89(2):33642.

2. Falco NA, Eriksson E. Facial nerve palsy in the newborn: incidence and outcome. Plast Reconstr Surg 1990;85(1):14.

3. Jemec B, Grobbelaar AO, Harrison DH. The abnormal nucleus as a cause of congenital facial palsy. Arch Dis Child 2000;83(3):256-8

4. Smith JD, Crumley RL, Harker LA. Facial paralysis in the newborn. Otolaryngol Head Neck Surg 1981;89(6):1021-4.

5. Parisier SC, Fayad JN, Kimmelman CP. Microtia, canalatresia, and middle ear anomalies. In: Ballenger's Otorhinolaryngol Head Neck Sur. $16^{\text {th }}$ edition, Snow JB, Ballenger JJ (Eds.), Williams \& Wilkins: Spain 2003:997-9.

6. Harrison DH. Treatment of infants with facial palsy. Arch Dis Child 1994;71(3):277-80.

7. Zuker RM, Goldberg CS, Manktelow RT. Facial animationin children with möbius syndrome after segmental gracilismuscle transplant. Plast Reconstr Surg 2000;106(1):1-8;discussion 9.

8. May M. Facial paralysis at birth: medico legal and clinical implications. Am J Otol 1995;16(6):711-2.

9. Laing JH, Harrison DH, Jones BM, Laing GJ. Is permanent congenital facial palsy caused by birth trauma? Arch Dis Child 1996;74(1):56-8.

How to cite this article: Kulkarni S, Verma S, Kavthekar SO, Singh BK. Congenital facial palsy with anotia and congenital heart disease in infants: A rare presentation. Int $J$ Med Paediatr Oncol 2019;5(4):149-50. 